\title{
TRABAJADORES Y RETIRADOS LA FLEXIBLE CONDICIÓN DE LOS MIGRANTES DEL OESTE Y NORTE DE EUROPA EN LOS DESTINOS TURÍSTICOS DE ESPAÑA ${ }^{1}$
}

\author{
Josefina Domínguez Mujica \\ Juan Manuel Parreño Castellano \\ Departamento de Geografía. Universidad de Las Palmas de Gran Canaria \\ jdominguez@dgeo.ulpgc.es, jparreno@dgeo.ulpgc.es
}

\section{RESUMEN}

En España residen numerosos jubilados extranjeros que proceden de países del oeste y norte de Europa, al igual que en otras áreas litorales del sur del continente. Este fenómeno se ha relacionado con procesos de inmigración residencial y con nuevas formas de especialización turístico-residencial, sin embargo, ciertos datos apuntan a la vinculación de algunos de dichos residentes con el mercado de trabajo turístico. El propósito de este artículo es desvelar la importancia de este nexo, a partir del estudio de la trayectoria laboral de los jubilados extranjeros que anteriormente habían sido inmigrantes laborales del sector turístico en España.

Key words: España, destinos turísticos, migrantes retirados extranjeros, trayectorias laborales, mercado de trabajo turístico.

Fecha de recepción: febrero 2012.

Fecha de aceptación: febrero 2013.

1 Este artículo se ha realizado en el marco del Proyecto I+D+i C200801000015 «Inmigración y trabajo en Canarias: análisis socioterritorial de la inmigración laboral y de la trayectoria socioprofesional de los inmigrados», financiado por la Agencia Canaria de Investigación, Innovación y Sociedad de la Información, de la que es investigadora principal la Dra. Josefina Domínguez Mujica. El trabajo fue presentado, de forma parcial, en noviembre de 2011 en Santiago de Chile en el marco de la Conferencia Geográfica Regional de la Unión Geográfica Internacional, cuya difusión se realizó a través de la web del Congreso, sin que mediara depósito legal alguno o reconocimiento mediante ISBN de dicho trabajo. 


\section{ABSTRACT}

There are many retired foreigners residing in Spain that come from Western and Northern Europe, as well as in other Southern areas. This phenomenon is related to the residential immigration processes and to new forms of tourist-residential specialization. However, there is some data linking such residents with the tourist industry. The main purpose of this article is to highlight these links from the analysis of the career of the retired foreigners that were employed previously in the tourist sector in Spain.

Key words: Spain, tourist destinations, foreign retired migrants, professional career, tourist labour market.

\section{INTRODUCCIÓN}

Los ámbitos turísticos han sido considerados un importante escenario en el que interactúan la movilidad humana y la propia actividad turística. Ahora bien, en pocas ocasiones se han relacionado el mercado de trabajo turístico, las trayectorias laborales de los migrantes y su condición de jubilados residentes en los destinos turísticos españoles. Este tipo de nexos tan sólo se ha explorado en unos pocos trabajos. O'Reilly (2000) y Casado-Díaz, Kaiser \& Warnes (2004) llamaron la atención acerca de la atracción laboral que ejerce la inmigración de retirados para jóvenes de su mismo origen geográfico, que ven oportunidades de empleo y de negocio prestando servicios a estos retirados en las zonas turísticas. Gustavson (2008), por su parte, señala que la presencia de migrantes retirados en España y sus conexiones con sus países de origen han creado ciertas infraestructuras de negocio como tiendas, restaurantes, bares y otro tipo de empresas comerciales. En cualquier caso, estas investigaciones constituyen una cierta excepción, puesto que la mayor parte de los trabajos sobre migrantes retirados vinculan su condición a la de haber pasado sus vacaciones, previamente, en esos destinos (Williams \& Hall, 2000; Rodríguez, 2001) o a la circunstancia de que se vieran atraídos por las promociones de las agencias inmobiliarias que ponían en el mercado urbanizaciones o inmuebles destinados a segundas residencias, y no a las trayectorias laborales de los migrantes.

Por tanto, con esta aportación tratamos de complementar los enfoques mencionados considerando como hipótesis de partida el hecho de que para el área de estudio, conformada por las provincias litorales del Mediterráneo y de Canarias y Baleares, el desarrollo de actividades en el negocio turístico origina un vínculo que convierte a los migrantes laborales del oeste y norte de Europa (Alemania, Austria, Bélgica, Dinamarca, Finlandia, Francia, Irlanda, Luxemburgo, Países Bajos, Reino Unido, Suecia, Suiza y Noruega) en migrantes retirados cuando alcanzan edades avanzadas, lo que contribuye a diluir los límites entre ambas categorías y permite redefinir el fenómeno del turismo residencial de jubilados. De este modo, pretendemos aproximarnos a las complejas formas de movilidad que descansan en un continuo entre migración permanente y turismo (Gustafson, 2002) y que han contribuido a las transformaciones económicas y sociales de la costa mediterránea y de los archipiélagos (Warnes, King \& Williams, 2005). 
En consecuencia, el artículo tiene dos objetivos principales. En primer lugar, aproximarnos a una cierta cuantificación del número de residentes mayores que han desarrollado una trayectoria laboral en nuestro país y, en segundo lugar, ahondar en la caracterización de esas trayectorias y en su dimensión territorial. Con esta finalidad, el trabajo se estructura del siguiente modo: en primer lugar, se desarrolla un epígrafe en el que se citan las fuentes y metodología empleadas. A continuación se incluye otro en el que se contextualiza la movilidad humana en la actual etapa de evolución del desarrollo turístico español. Los tercer y cuarto epígrafes se centran en la caracterización del mercado de trabajo de los migrantes activos del oeste y norte de Europa en las áreas turísticas españolas y de los migrantes retirados de estos países. En el quinto se intenta demostrar la relación entre ambos fenómenos (migración laboral y residencial de europeos en las zonas turísticas) a partir del análisis de las trayectorias laborales y, por último, se dedica un apartado a las conclusiones.

\section{FUENTES Y METODOLOGÍA DE ANÁLISIS}

En la mayor parte de las investigaciones sobre migración de retirados se alude a la dificultad que representa cuantificarla y caracterizarla, y que esto tiene que ver con una serie de problemas básicos que derivan de que no se dispone de registros de población específicos sobre dichos grupos, sino tan sólo de datos demográficos de carácter administrativo (King, Warnes \& Williams, 2000). En el caso de España, se cumple completamente este aserto (Rodríguez, et al., 2005), de tal modo que las diferentes fuentes de carácter estadístico que pueden resultar más apropiadas permiten una aproximación solamente parcial al tema de estudio. En nuestro caso hemos utilizado tres fuentes de datos.

En primer lugar, la explotación estadística del padrón, un registro que ofrece datos sobre la población con residencia principal, permanente o habitual en el municipio, por sexo, edad, lugar de nacimiento, lugar de residencia y nacionalidad, con fecha de uno de enero de cada año. De especial importancia ha sido la consulta de las microfichas de la explotación estadística del padrón para el año 2011, año a partir del cual el INE ofrece este tipo de microdatos para los municipios de más de 10.000 habitantes. La localización precisa de los residentes de más de 65 años en los municipios de las provincias mediterráneas y de Canarias procede de dicha fuente (con excepción de municipios pequeños).

En este caso, no hemos usado el Censo de Población, que contiene la información referida a las características sociodemográficas de los residentes de los países de nacimiento y ámbitos geográficos seleccionados y a la población vinculada (personas con residencia habitual en España, que tienen algún tipo de vinculación habitual con el municipio de referencia, ya sea porque viven, trabajan o estudian allí o porque no siendo su residencia habitual, pasan allí ciertos período de tiempo) porque el calendario de difusión del Censo de 2011 tan sólo nos ha permitido disponer, a principios de 2013, de tablas de población por sexo, edad y país de nacimiento de los municipios de más de 20.000 habitantes, una información completamente insuficiente para los propósitos de la investigación.

La segunda fuente empleada ha sido el registro de trabajadores afiliados al sistema de la Seguridad Social española. La Tesorería General de la Seguridad Social ofrece series históricas de altas laborales o situación asimilada desde el año 2000 a escala provincial por regímenes, nacionalidad y género. Esto nos ha permitido valorar la importancia de la pobla- 
ción extranjera de las nacionalidades que nos interesan en el mercado laboral de la zona de estudio.

El registro estadístico fundamental para la elaboración de este trabajo ha sido la Muestra Continua de Vidas Laborales (MCVL), disponible desde el año 2004 y que se compone de un conjunto organizado de microdatos individuales y anónimos, extraídos de los registros de la Seguridad Social y completados con datos fiscales y del padrón continuo de personas activas (ocupados y desempleados) y no activas, que mantienen una relación administrativa con la Seguridad Social española (Durán, 2007). Se trata de la única de las fuentes mencionadas que nos permite adoptar una perspectiva de análisis longitudinal. Por una parte, nos brinda la posibilidad de investigar las trayectorias laborales de los extranjeros residentes en España a partir de la explotación de la base de datos de los afiliados a la Seguridad Social y, por otra, de los perceptores de pensiones. Desde su creación en 2004, debido a la estructura en panel de la muestra, todos los años se actualiza la información de las personas que la componen, mientras éstas mantengan su vínculo con la Seguridad Social. Esta característica es la que da especial interés a la MCVL como fuente de información y ha justificado algunas aproximaciones metodológicas para su tratamiento (García Pérez, 2008).

Ahora bien, conviene tener en cuenta que la MCVL, al suponer el 4\% de la población y realizarse mediante un muestreo aleatorio simple, presenta un nivel de confianza del 95,5\% y un error muestral del 0,09\% para un supuesto de p y q del 50\%, únicamente para datos globales, por lo que cuando nos aproximamos a la realidad de un determinado ámbito espacial, como las provincias del arco mediterráneo y los dos archipiélagos, o a un colectivo específico, europeos del oeste y norte de Europa, el uso que se hace de la información hay que interpretarlo como una aproximación al conocimiento. No obstante, el gran tamaño de la muestra permite llegar a niveles de desagregación muy detallados, con significación estadística de las estimaciones, con bajos niveles de error, difíciles de lograr a través de otras fuentes. De ahí que se hayan realizado algunas investigaciones que dan validez a los resultados procedentes de la muestra, como el análisis de la trayectoria laboral y la inserción de población inmigrante (López Roldán, 2011); el análisis de las mujeres inmigrantes y nacionales en términos comparativos (Cebrián y otros, 2007) o la movilidad ocupacional vertical de los inmigrantes (Martín-Artiles; López-Roldán y Molina, 2011). En otras ocasiones se han seleccionado los datos en función de criterios geográficos, como en el estudio de los itinerarios laborales en la Comunidad de Madrid (Sáez, 2007), y tampoco faltan investigaciones sobre colectivos más específicos, como el que se dedica a la relación entre género y temporalidad entre los profesionales superiores del sector sanitario (Dolado y Felgueroso, 2007) o a diversos aspectos del mercado de trabajo de las personas con discapacidad (Rodríguez, 2010).

Por otra parte, ninguno de estos trabajos se ha realizado desde la óptica de la Geodemografía, lo que confiere cierta novedad a este artículo, pues la mayor parte de las dificultades para obtener información sobre migrantes de Europa occidental retirados en España se ha resuelto, desde la perspectiva geográfica, con encuestas diseñadas ex profeso para analizar esta realidad o bien mediante otro tipo de procedimientos cualitativos, como la observación participante, los grupos focalizados, las entrevistas a expertos, las historias de vida, y la combinación de estas distintas metodologías de trabajo (Bozic, 2006). En todos ellos se ha obtenido una menor información acerca de las trayectorias laborales de los retirados y, sobre todo, de sus vínculos de trabajo con los espacios donde deciden retirarse. Por este motivo, la 
Muestra Continua de Vidas Laborales se ha revelado una fuente especialmente valiosa para la reconstrucción de trayectorias laborales de los retirados de los países del oeste y norte de Europa que trabajaron en España.

Otras fuentes de información como las microfichas de la Estadística de Variaciones Residenciales (EVR) del INE, los certificados de registro o tarjetas de residencia expedidos por el Ministerio del Interior o la propia Encuesta Nacional del Inmigrantes (ENI) del INE, sólo han sido consultadas de forma tangencial en esta investigación.

Desde un punto de vista metodológico, el trabajo con la Muestra Continua de Vidas Laborales se inició procediendo a descargar los datos de los distintos ficheros en hojas de cálculo del programa SPSS. Se volcó la información de los ficheros de afiliación (afilia, según la denominación utilizada por los ficheros originales), la más amplia, en una de ellas; la de prestaciones (presta, en su argot) en otra, los datos personales (personal) en otra más y los de convivencia (convive) en una última. A partir de ese momento se procedió a realizar distintos filtros en la hoja de cálculo de los datos personales mediante la herramienta de selección por atributos en determinados campos (nacionalidad, edad y provincias de residencia). A continuación se localizaron en el fichero de prestaciones los valores ID (identificación única por individuo), aislando los registros correspondientes del conjunto. Dentro de él despreciamos los de personas cuya prestación estaba ligada sólo a situaciones de orfandad, discapacidad o viudedad. Posteriormente, con los registros ID resultantes, procedimos a rescatar la información de dichas personas que contenía el fichero de afiliación y, a continuación, se procedió a reunir todos ellos en una misma hoja de cálculo, de forma que el resultado fue una base de datos de las personas que percibían prestación y habían trabajado con anterioridad. El análisis se realizó, a partir de este punto, con consultas específicas.

\section{LA MOVILIDAD HUMANA EN LOS DESTINOS TURÍSTICOS}

La evolución turística ha sido asociada a distintos procesos de internacionalización, ya sea del mundo del trabajo, ya de la evolución tecnológica, ya de la extensión de los modos de vida y pautas culturales que el propio desarrollo del turismo ha retroalimentado. La internacionalización o globalización del trabajo y la inversión en los destinos turísticos se ha acompañado, por tanto, de una intensa movilidad humana, máxime en el contexto del actual régimen de acumulación posfordista en el que la flexibilidad funcional de la fuerza de trabajo cualificada y la numérica de los trabajadores no cualificados lo ha propiciado (Ioannides \& Debbage, 1997). Como señalan Domínguez, González \& Parreño «la demanda de calidad y la personalización de los servicios turísticos estimularon la contratación de trabajadores cualificados de Europa occidental (especialmente alemanes y británicos), mientras que la necesidad de ofrecer a la clase media europea productos de calidad a precios razonables contribuyó a mantener a un numeroso grupo de trabajadores con bajos salarios. Esta demanda no pudo ser cubierta por la población española, que había alcanzado un alto nivel de cualificación, sino con latinoamericanos y africanos» (2011, 596). Consecuentemente, como se apunta desde la visión re-estructurante, la movilidad humana se teoriza como una condición necesaria para el sistema económico y, al mismo tiempo, como su consecuencia.

Pero además, el desarrollo de las comunicaciones, la creación de espacios económicos internacionales, la proliferación de negocios trasnacionales, así como el desarrollo de la 
propiedad residencial, una pauta de consumo post-moderna que se ha visto reforzada en la medida en que cada vez es más fácil y tiene mayor seguridad jurídica el alquiler o la compra de propiedades inmobiliarias en el extranjero, han aumentado la diversidad de flujos y han complicado la clasificación de las personas móviles.

En este sentido, desde los años noventa del siglo XX y, especialmente, en la primera década del siglo XXI, los estudios de movilidad humana han dado cabida al análisis de grupos de muy variada condición, entre los que se hallan los denominados migrantes mayores, migrantes retirados, turistas jubilados o residentes extranjeros retirados (Parreño, Díaz \& Domínguez, 2011). Es numerosa la bibliografía que puede consultarse acerca de este tipo de movilidad, si bien no hay unanimidad en su definición y caracterización, pues para algunos autores se trata de procesos migratorios, mientras que otros definen a sus protagonistas como turistas.

Es probable que ello se deba al carácter transnacional que implica este tipo de movilidad (Gustafson, 2008), así como al hecho de que se trate de un proceso flexible (O’Reilly, 2003), que vuelve compleja la diferenciación entre turistas y migrantes, cuando intercambian sus roles de actividad e inactividad laboral. Se suele clasificar este tipo de movilidad como turística porque se considera que se diferencia de la turística tan sólo porque la estancia es de larga duración, aunque discontinua a lo largo del año y estacional en muchos casos (Vera, 1997, Leontidou \& Marmaras, 2001) y porque no implica alojamientos reglados. Al mismo tiempo, los movimientos de carácter turístico tienden a crear una cierta diversificación de los flujos de personas móviles, de manera que unos movimientos tienden a reforzar otros (Rodríguez, Casado-Díaz \& Huber, 2005) y la permanencia de este fenómeno en el tiempo suele potenciar redes sociales dependientes del turismo (Williams \& Montanari, 1995), que pueden dar lugar a una gran complejidad de situaciones que terminan por difuminar los límites entre turistas y migrantes-residentes (Hall \& Müller, 2004; McIntyre, Williams \& McHugh, 2006). En un sentido opuesto, se definirían a estos grupos como migrantes cuando se estima concluyente el 'lifestyle migration', es decir, que se trata de personas que se 'relocalizan' buscando un mayor bienestar (Benson \& O'Reilly, 2009).

Esta complejidad se incrementa más aún cuando consideramos el devenir vital de cada individuo, lo que motiva que una persona pueda cambiar de condición dependiendo de su trayectoria y, en cualquier caso, de manera mucho más flexible, dificultando la clasificación de las personas como activos o retirados y turistas o migrantes. Todo este contexto sobre la movilidad humana ha generado que algunos investigadores se hayan hecho eco de la necesidad de adoptar nuevas conceptualizaciones, ya que cada vez es más variada la tipología de personas que se mueven al dictado de causas, factores o situaciones que se vuelven difíciles de abarcar o de clasificar. En otros términos, se trata de desvelar para aquellas áreas como la que abordamos en este estudio, «the three forms of tourism-related migration: retirement migrants, entrepreneurial migrants and consumption-led economically-active migrants» (O'Reilly, 2003, 301), indagando en las relaciones cambiantes que estas formas guardan entre sí y que han sido abordadas desde una perspectiva cualitativa por distintos autores (O'Reilly, 2003; Stone and Stubbs, 2007; Haug, Dann \& Mehmetoglu, 2007; Gustafson, 2008 , etc.). 
Figura 1

AFILIACIÓN A LA SEGURIDAD SOCIAL ESPAÑOLA DE TRABAJADORES DEL OESTE Y NORTE DE EUROPA

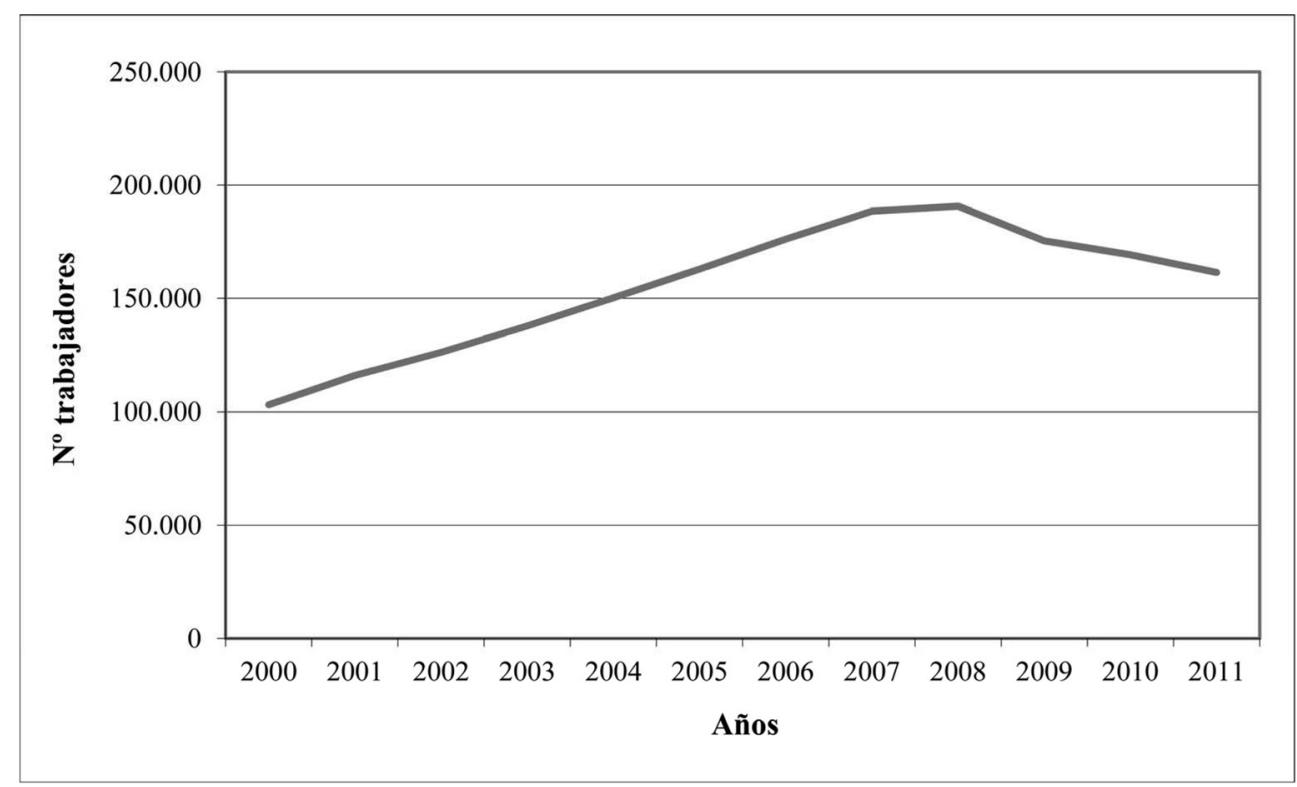

Fuente: Secretaría de Estado de la Seguridad Social. Ministerio de Empleo y Seguridad Social.

\section{LA INTERNACIONALIZACIÓN DEL MERCADO DE TRABAJO EN LAS ÁREAS TURÍSTICAS ESPAÑOLAS}

El proceso de internacionalización que implica la actividad turística ha movilizado, históricamente, un número de trabajadores desde los países de los que proceden los capitales que han financiado o promovido el negocio turístico. En el caso de España, desde los más lejanos antecedentes de desarrollo turístico, se reconoce la simultánea presencia de inversores y de agentes cualificados, trabajadores especializados, técnicos, trabajadores de actividades complementarias, etc. de origen británico y alemán y de otros países de Europa occidental, en los principales enclaves turísticos. A modo de ejemplo de esta histórica vinculación, cuando a fines de los años ochenta, aún se exigía a los trabajadores por cuenta ajena de la ex Europa de los doce la solicitud de permiso de trabajo para realizar dichas actividades, estos trabajadores extranjeros ostentaban la primera posición en relación con los distintos grupos de nacionalidades en Canarias (Domínguez, 1996).

En todos los enclaves turísticos, en aquellas fechas, tenían un peso muy destacado las solicitudes de permisos temporales de jóvenes que querían desempeñar, durante un breve periodo, actividades propias de la asistencia a grupos turísticos y, en sentido complementario, eran numerosos los empresarios extranjeros de aquellos orígenes, que empleaban trabajadores de su misma procedencia, fundamentalmente en los subsectores de la hostelería, los transportes y comunicaciones y las actividades inmobiliarias y de servicios prestados a empresas. 
Esta especialización del mercado de trabajo se ha mantenido a lo largo de los años y es probable que se haya incrementado en el siglo XXI, al ritmo de un empleo cada vez más flexible y de un proceso de movilidad circular entre empresas y actividades. Las cifras de afiliación de trabajadores del oeste y norte de Europa a la Seguridad Social española así lo pone de manifiesto (figura 1).

Para el año 2009, los trabajadores de los países de Europa occidental y nórdica (Suecia, Finlandia, Dinamarca, Reino Unido, Irlanda, Países Bajos, Bélgica, Luxemburgo, Francia, Alemania, Suiza, Austria y Grecia²) que residían en las provincias litorales de Girona, Barcelona, Tarragona, Castellón, Valencia, Alicante, Murcia, Almería, Granada, Málaga y Cádiz, y en los archipiélagos de Baleares y Canarias, que estaban en situación de alta en la Seguridad Social española, en la Muestra Continua de Vidas Laborales se elevaban a 7.767, de los que 2.674 eran británicos y 1.971 alemanes, lo que equivalía a un 79\% de las personas de dichos orígenes que estaban dadas de alta en la Muestra para toda España (9.863). Si consideramos que el número total de afiliados en España, de aquellos orígenes, alcanzaba en dicha fecha de referencia la cifra de 176.237 personas, según datos de la Secretaría de Estado de la Seguridad Social, a las provincias del ámbito de estudio podrían corresponderles unos 130.000 trabajadores, lo que nos informa de la importancia de los trabajadores de estas nacionalidades. Este dato también se ve reforzado con la información del número de extranjeros que, según la Dirección General de Relaciones Internacionales y Extranjería del Ministerio del Interior, tenían un certificado de registro o tarjeta de residencia en vigor en toda España, en el mismo año, concretamente, 222.000 británicos y casi 110.000 alemanes.

Los datos pormenorizados de la Muestra nos permiten valorar la relación entre estos trabajadores extranjeros y la actividad turística. La mayor parte de los afiliados cotizaba en el régimen general de la Seguridad Social, en el grupo de auxiliares administrativos y, secundariamente, en la categoría de oficiales de primera y segunda, siendo las actividades declaradas, fundamentalmente, la hostelería (24,3\%), las actividades administrativas o de servicios auxiliares $(13,3 \%)$ y el comercio $(13,2 \%)$. Dentro de la hostelería, la mayor parte de los trabajadores se empleaba en restauración $(73,4 \%)$ y el resto en servicios de alojamiento, mientras que en el sector de actividades administrativas, los que realizaban actividades temporales, en su mayoría de apoyo a grupos de turistas, correspondían a una cuarta parte $(25,8 \%)$ y los que trabajaban en agencias de viajes y operadores turísticos suponían el 21,4\%. En servicios de alquiler se registraba un $18,7 \%$ de los movimientos, fundamentalmente en alquiler de vehículos de motor. Además, en el capítulo concreto de la hostelería se empleaba la mayor parte de los oficiales de tercera y especialistas que había en todas las profesiones clasificadas, siendo este sector de la hostelería el que daba trabajo, mayoritariamente, a británicos (figura 2).

En cuanto al lugar de ejercicio profesional, estos trabajadores, que residían en la misma provincia donde se hallaban afiliados, alcanzaban valores más significativos en Baleares, Canarias, Alicante (Costa Blanca) y Málaga (Costa del Sol), además de en Barcelona. Desde una perspectiva complementaria, eran más numerosos los colectivos de trabajadores alemanes en Baleares y Las Palmas (Canarias) y de británicos en Alicante, Málaga y Santa Cruz de

2 Hemos considerado a los trabajadores griegos junto a los demás porque aparecían agrupados en una categoría conjunta, aunque su peso es insignificante y tampoco cumplen el perfil de los demás trabajadores del norte y centro de Europa. 


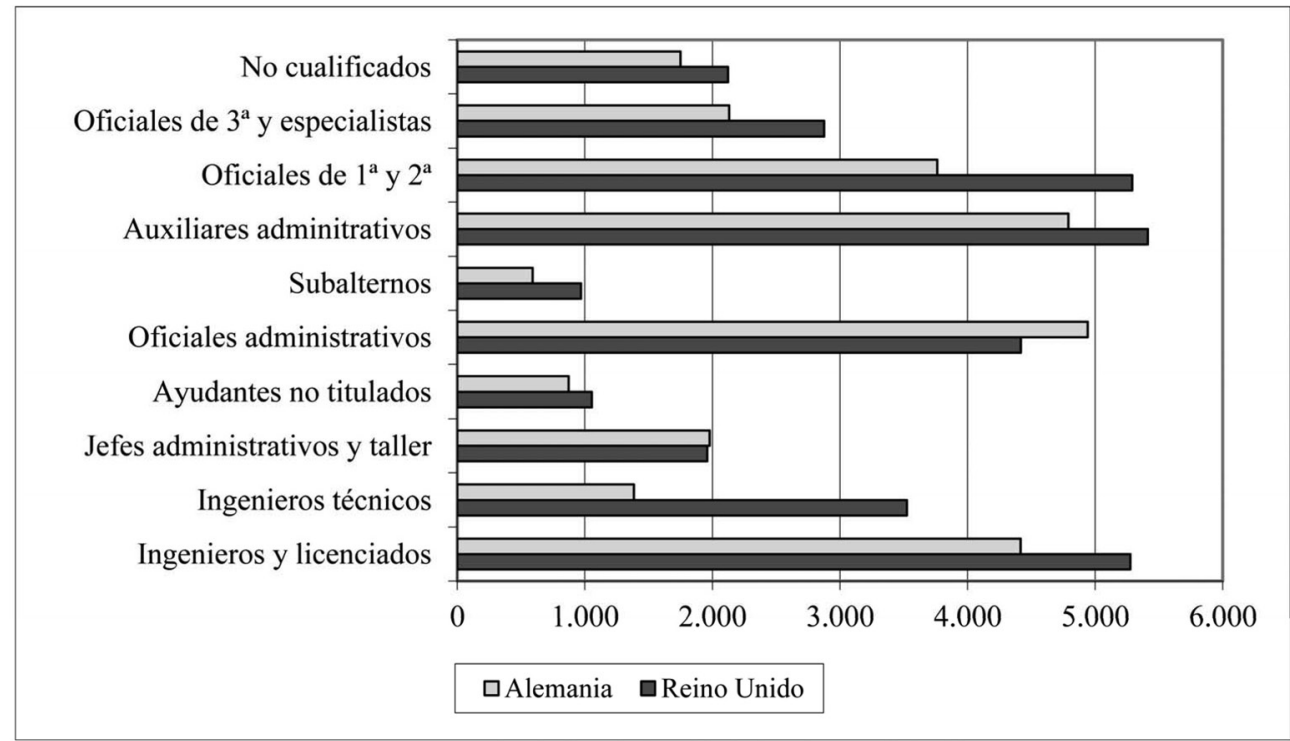

Fuente: Muestra Continua de Vidas Laborales. Ministerio de Empleo y Seguridad Social.

Tenerife (Canarias). En la provincia de Barcelona, el fenómeno de la actividad laboral excede a la influencia del negocio turístico, siendo un factor explicativo de mucha mayor importancia la especialización urbana de la capital y de su área de influencia metropolitana. En Girona (Costa Brava), por su parte, la presencia de trabajadores franceses era notable.

Desde un punto de vista biodemográfico, predominaban los hombres (111 hombres por cada 100 mujeres), aunque las cifras eran superiores en el caso de los trabajadores franceses (sex ratio de 124), mientras que los alemanes guardaban un mayor equilibrio (101 trabajadores por cada 100 trabajadoras), lo que demuestra una incorporación de género al mercado laboral de las áreas turísticas más pareja. La edad media de estos trabajadores era avanzada en relación a los colectivos de inmigración que ha recibido España, concretamente, de 40,7 años. En el caso de los británicos y alemanes, aún ascendía más, alcanzando dicho promedio 42,4 y 40,8 años, respectivamente. En ello influía el que haya personas en edades de jubilación que siguen ejerciendo una actividad remunerada como asalariados $\mathrm{y}$, sobre todo, como autónomos.

\section{LA INMIGRACIÓN DE RETIRADOS DE PAÍSES DEL OESTE Y NORTE DE EUROPA EN LOS DESTINOS TURÍSTICOS ESPAÑOLES}

Mientras que la investigación sobre la inmigración internacional de retirados en Francia, Gran Bretaña, Países Bajos y otros países europeos, se inició en los años setenta, en España 


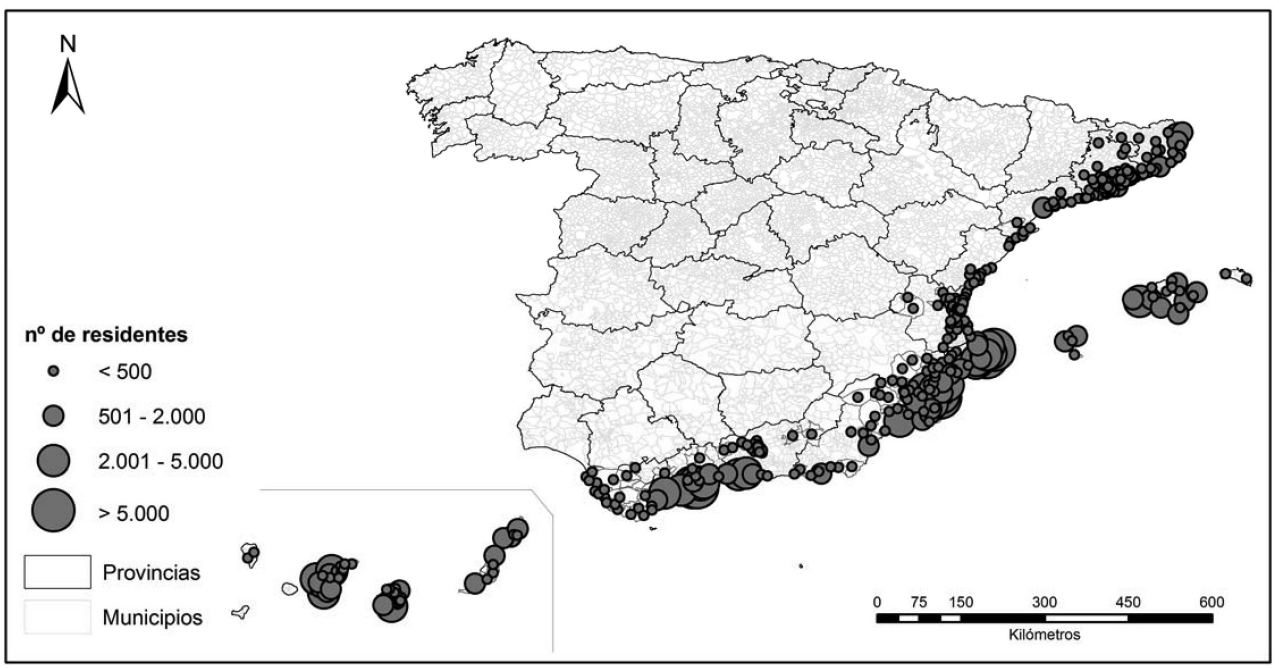

Fuente: Microfichas de la explotación estadística del padrón (INE).

comenzó a mediados de los noventa (Casado-Díaz, Kaiser \& Warnes, 2004), entre otras razones, por la opacidad en la medición de este fenómeno, que hacía difícil la estimación del flujo de dichas personas. Eso ha llevado a que en la mayor parte de los estudios realizados con técnicas cuantitativas se haya adoptado, como criterio numérico, el de los residentes de más de 55, 60 o 65 años que provienen de los países objeto de nuestro estudio ${ }^{3}$. Según datos de la explotación estadística del padrón de 2009, los residentes de más de 65 años del oeste y norte de Europa alcanzaban la cifra de 211.261, lo que equivalía al 20\% de la población de estos orígenes que vivía en España. Si tenemos en cuenta que muchos adultos se retiran antes de cumplir los 65 años, la proporción de personas que pueden estar en una situación de retiro se podría incrementar hasta el $30 \%$. Estas cifras se elevan aún más si consideramos tan sólo las provincias del litoral mediterráneo y los dos archipiélagos, en las que residían 191.327 gerontoinmigrantes, es decir, el 90,6\% de los residentes de esta procedencia y edad, de toda España. Además, según la Estadística de Variaciones Residenciales, en el año 2009 se produjeron 35.771 altas de extranjeros de estos orígenes en el área de estudio, lo que equivale a más del $83 \%$ del total de las que se dieron en el conjunto de España. Se trata, precisamente, de las provincias que mencionábamos anteriormente, cuando analizábamos la estructura del mercado laboral de los inmigrantes del oeste y norte de Europa.

Desde una perspectiva municipal, se aprecian niveles de concentración notables en los municipios próximos a la costa, sobre todo en Alicante (Costa Blanca), Málaga (Costa del

3 Los países seleccionados son: Alemania, Austria, Bélgica, Dinamarca, Finlandia, Francia, Irlanda, Luxemburgo, Países Bajos, Reino Unido, Suecia y Noruega, aunque no podemos considerar los de Noruega, en la MCVL, porque vienen agrupados con otros países que no interesan en este estudio. 
Sol) y los dos archipiélagos, aunque el secreto estadístico no nos permite apreciar en toda su magnitud este fenómeno, pues las microfichas de la explotación estadística del padrón no nos ofrecen datos de los municipios de menos de 10.000 habitantes, para las variables seleccionadas (figura 3).

Para algunos autores, la concentración geográfica de estos europeos retirados está relacionada con ámbitos territoriales, «donde la política de promoción de suelo residencial, esencialmente para turistas que luego pueden convertirse en residentes permanentes, la existencia de infraestructuras turísticas consolidadas o la presencia de una masa consolidada de residentes extranjeros (a veces sólo turistas de mayor duración) hacen posible estructuras económicas orientadas a su servicio» (Rodríguez, Casado-Díaz \& Huber, 2005, 30). Ahora bien, ¿no habría de contemplarse entre estos factores de localización el de la actividad laboral o empresarial de muchos de los residentes en una etapa previa de su vida o en los propios años de retiro, ya sea en el negocio turístico o en actividades complementarias? La respuesta a este interrogante podemos encontrarla en los ficheros de las prestaciones que perciben los trabajadores de esta procedencia geográfica que habían cotizado en España y que residen en dichas provincias ${ }^{4}$, así como en los datos de su anterior afiliación como trabajadores, una aproximación longitudinal que nos permite la Muestra Continua de Vidas Laborales.

\section{INMIGRACIÓN RESIDENCIAL Y MERCADO DE TRABAJO: LA PERSPECTIVA DE LAS TRA- YECTORIAS LABORALES}

Según la Muestra Continua de Vidas Laborales, 311 migrantes del oeste y norte de Europa, que recibían una prestación por jubilación de la Seguridad Social española, residían en el área de estudio en 2009. Si contrastamos este número de jubilados que habían cotizado anteriormente como trabajadores, con el número de afiliados a la Seguridad Social española de los orígenes y provincias considerados en 2009, la proporción equivale a un $4 \%$. Se trata, por tanto, de una pequeña cuantía, si bien, habría que tener en cuenta que algunos de los activos siguen trabajando en edades de jubilación mientras que otros han podido fallecer antes de poder recibir prestaciones o no trabajaron el número de años necesario para percibirlas o, simplemente, regresaron a sus países de origen y las perciben allí. Es decir, que entre los migrantes retirados procedentes del oeste y norte de Europa, los que habían trabajado anteriormente en España tienen una cierta importancia en relación con la población de esas nacionalidades afiliadas a la Seguridad Social española.

Ese porcentaje se repite prácticamente igual $(3,9 \%)$ si contrastamos la población de jubilados de las nacionalidades consideradas de la muestra con los gerontoinmigrantes empadronados en las provincias analizadas, aunque este porcentaje sería a todas luces mayor si consideráramos como unidad de medida el hogar. En cualquier caso, desde el punto de vista cuantitativo, estamos ante un fenómeno minoritario en relación con la magnitud que ha

4 La importancia del trabajo de inmigrantes del oeste y norte de Europa en España no la determinan sólo las cifras de los que cobran una pensión del estado español en estas zonas, sino también, la de aquéllos que pueden cobrarla en su país de origen, dato este último más difícil de determinar porque a los extranjeros que perciben pensiones en el extranjero se han de sumar los españoles que perciben pensiones en el extranjero, en casi todos los casos, a consecuencia de la emigración. 
alcanzado la migración residencial, en especial entre algunas nacionalidades (británicos y alemanes) y algunas provincias (Alicante, Málaga y los dos archipiélagos).

Según la Muestra de 2009, el perfil de estos residentes corresponde a personas de más de 60 años que habían cotizado como promedio 5,3 años a la Seguridad Social española, dándose situaciones de menos de un año y otras de hasta 27. La mayor parte de ellos era de nacionalidad alemana $(38,3 \%)$ y británica $(24,1 \%)$ y casi un $70 \%$ de dichos jubilados eran hombres. En cuanto a los hábitos de convivencia de este colectivo, superaban el tercio los que vivían solos, siendo un poco mayor el número de hombres que de mujeres $(57,6 \%$ frente a un $42,4 \%$, respectivamente). Un $41 \%$ vivía en pareja, situación en la que el titular de la prestación era un hombre en un $80 \%$ de los casos. En un 11,3\% de los hogares de los jubilados estaban formados por más de dos personas, lo que habitualmente se correspondía con hogares familiares formados por cónyuges y descendientes. La estructura de los hogares, alejada de la que se presenta entre migrantes laborales de otras nacionalidades, parece indicarnos que estamos ante una situación de arraigo.

Desde un punto de vista geográfico, en los archipiélagos de Canarias y Baleares residía más de un tercio del conjunto, seguidos, a continuación, por las provincias de Barcelona, Alicante y Málaga, con cifras que rondaban, en cada caso, el 13\%. Ello demuestra el mismo patrón de comportamiento territorial que se apreciaba por parte de los trabajadores, según los datos de afiliación comentados y que también puede observarse en la distribución territorial de residentes a la que apuntan los datos de la explotación del padrón, tal y como mencionábamos anteriormente. En cualquier caso, queda claro el estrecho nexo que guarda la especialización turística con la atracción de trabajadores procedentes de los lugares de los que han provenido muchas de las inversiones en el sector y, también, que tras su radicación laboral en España se convierten, en un cierto número, en gerontoresidentes.

Para ahondar más en este proceso que los lleva de trabajadores a gerontoresidentes, es necesario avanzar en el conocimiento de sus trayectorias laborales. Para ello disponemos de una información completa del pasado laboral de 263 jubilados, lo que supone 1.431 movimientos en el registro de afiliación a la Seguridad Social.

La primera conclusión que nos permite el análisis de las trayectorias laborales de estos 263 jubilados es que, o bien desarrollaron actividades de media y alta cualificación, mayoritariamente en las funciones propias del mercado laboral de los destinos turísticos, o bien los que se quedan son los más cualificados. El grupo o categoría de cotización así lo pone de manifiesto. En un 18,5\% fueron oficiales de primera y segunda, los oficiales administrativos fueron un $17,5 \%$ y los ingenieros y licenciados un 13,7\%. Estas actividades las desempeñaron sobre todo en los sectores de la hostelería $(26,9 \%)$ y otros servicios administrativos $(14,1 \%)$, un dato que también corrobora el hecho de que, desde un punto de vista geográfico, la localización de la empresa donde desarrollaron su actividad laboral estos jubilados corresponde, principalmente, a Baleares $(21,0 \%)$, Canarias $(20,6 \%)$ y las provincias de Barcelona $(16,9 \%)$, Madrid (13,2\%), Alicante (7,4\%), Girona (7,4\%), Málaga $(6,2 \%)$ y Valencia, 3,3\%.

En segundo lugar, se puede afirmar que hay correspondencia entre las áreas geográficas donde trabajaron y aquéllas donde recibían prestación, pues la mayoría de los que vivían en Alicante, Baleares, Barcelona y Valencia, había trabajado en dichas provincias, mientras que los de Girona lo habían hecho, además de en esta provincia, también en Baleares y Barcelona y los de Tarragona, en Barcelona. Los de Murcia trabajaron casi por igual en la misma 
provincia y en Madrid, y los de Málaga tanto en Madrid como, secundariamente, en Málaga y Baleares. Los de Canarias trabajaron en las mismas provincias del archipiélago, pero también en Baleares. Por tanto, casi todos decidieron pasar su vejez en los mismos lugares donde habían trabajado o en zonas de especialización turística (archipiélagos), aunque su ejercicio profesional se hubiera desarrollado, previamente, en grandes ciudades como Madrid y Barcelona. Ello demuestra una de las hipótesis de trabajo iniciales, es decir, que el desempeño de ciertas actividades laborales en el propio negocio turístico origina un vínculo que convierte a los migrantes laborales en migrantes retirados, al cabo de una serie de años, y ello contribuye a diluir los límites entre ambas categorías, máxime si se tiene en cuenta que algunos de los residentes en edad de jubilación siguen trabajando.

En tercer lugar, el régimen de cotización nos informa de que, en términos relativos, los que tienen su propio negocio o tienen un empleo asalariado más estable se convierten en gerontoinmigrantes en una mayor proporción. Si bien la mayor parte de estos trabajadores cotizó por el régimen general (70\%), un 23,5\% lo hizo en concepto de trabajador autónomo ${ }^{5}$, lo que marca una importante diferencia con respecto a la estructura del mercado de trabajo de la población española y de los trabajadores en España. El peso de los autónomos pone de manifiesto que muchos de ellos fueron emprendedores en las distintas actividades que fomenta la especialización turística, especialmente en el sector de la hostelería (pubs, restaurantes, bares, etc.) pero también que parece más probable que se conviertan en jubilados residentes que los asalariados.

En el mismo sentido, determinadas actividades relacionadas con el sector turístico parecen generar más arraigo y, por tanto, favorecer la permanencia del trabajador tras la jubilación. Concretamente, de los jubilados que trabajaron en la hostelería, un 61,9\% se empleaba en actividades de alojamiento y el resto en restauración, lo que contrasta con los datos del empleo que ejercían los activos en 2009, en el que tenía más peso la restauración que el alojamiento. En el caso de las actividades administrativas, el $43 \%$ trabajó en agencias mayoristas, un $30 \%$ en actividades temporales y un $30 \%$ en servicios de alquiler, datos que son opuestos a los de los actuales activos, dado el mayor peso que tienen hoy los empleados temporales entre los trabajadores de estas procedencias, con respecto al empleo en agencias de viajes, en operadores turísticos y en servicios de alquiler. Esto nos lleva a la hipótesis de que haya podido cambiar la especialización del mercado de trabajo turístico o a que ha aumentado la temporalidad del empleo en España, pero también al hecho de que el ejercicio de actividades de alojamiento y de tareas de gestión en agencias mayoristas parece generar mayor arraigo que, por ejemplo, el desempeño de funciones temporales de asistencia a grupos turísticos, que en su mayor parte las realizan ciertos jóvenes que las consideran una primera experiencia laboral. De confirmarse este extremo, ello relacionaría la migración de retiro con niveles más altos de cualificación en el ejercicio laboral, como apuntamos anteriormente, o con profesiones que representan menor temporalidad.

Por último, se aprecia que se trata de un colectivo cuya movilidad entre distintas actividades es notable, como pone de manifiesto el hecho de que cambiara su régimen laboral en distintos momentos de su vida, sobre todo en el caso de los autónomos. Por ejemplo, los jubilados que cobran a través del régimen de trabajadores autónomos, desempeñaron el 58,8\% de su actividad como tales y el 34,0\% a través del régimen general. A la inversa, los que cobran

5 Los demás trabajadores cotizaron por regímenes especiales. 
a través del régimen general, estuvieron casi siempre en ese régimen (93,5\%), y en un 3,7\% de los casos como autónomos, todo lo cual apunta a que tuvieron capacidad de adaptación a la diversidad de oportunidades laborales y de negocio que ofrece el mercado laboral de los destinos turísticos o que los que tienen mayor capacidad de adaptación al mercado, se arraiguen también más fácilmente.

Por tanto, a partir del análisis de las trayectorias laborales podemos afirmar, por un lado, que la cualificación, la estabilidad laboral y la capacidad de adaptación al mercado y de emprendimiento parece favorecer que el trabajador de estas nacionalidades termine convirtiéndose en jubilado residente $\mathrm{y}$, por otro, que los destinos turísticos integran a estos trabajadores una vez que finaliza su vida laboral.

\section{CONCLUSIONES}

El estudio de la relación que guarda la movilidad humana con la especialización productiva de los destinos turísticos explica el interés de analizar la trayectoria laboral de los migrantes laborales y de los jubilados que residen en destinos turísticos. Dado que la movilidad humana es una condición necesaria para el sistema económico y, al mismo tiempo, su consecuencia, el mercado de trabajo turístico no sólo genera atracción para ciertos trabajadores, sino también para migrantes retirados. La novedad que aporta el estudio de las trayectorias laborales de los migrantes radica en que nos permite reconocer la combinación de las situaciones de actividad y retiro, pues algunos migrantes retirados son antiguos trabajadores del sector turístico o personas en activo en edades de jubilación.

En las provincias litorales y en los dos archipiélagos, donde reside en España la mayor parte de los jubilados procedentes de Europa nórdica y occidental, se reconoce la simultánea presencia de la mayoría de los inversores y agentes cualificados, personal especializado, técnicos, trabajadores auxiliares y empleados en actividades complementarias del sector turístico, de este origen. El nexo de los activos y jubilados con el negocio turístico lo pone de manifiesto el hecho de que haya una proporción de en torno al cuatro por ciento de retirados que había trabajado anteriormente en el sector turístico, cotizando para la Seguridad Social española. Estos retirados tienen una vinculación de larga duración con las áreas de especialización turística, como demuestra el hecho de que vivan, mayoritariamente, allí donde habían trabajado, o en otra provincia turística, sobre todo en el caso de los alemanes, y que el periodo medio de cotización fuera de más de cinco años. Por otra parte, son aquéllos que habían ejercido profesiones de menor temporalidad y de más alta cualificación los que reconocemos mayoritariamente entre los retirados, al mismo tiempo que se aprecia que algunos de los que se hallan en edad de jubilación siguen siendo activos.

Por tanto, una fuente escasamente utilizada en Geodemografía, cual es la Muestra Continua de Vidas Laborales, nos ha brindado una perspectiva longitudinal que no ofrecen otras fuentes demográficas como la explotación estadística del padrón o las microfichas de la estadística de variaciones residenciales. Ello nos ha permitido caracterizar la trayectoria laboral de los migrantes retirados que habían desarrollado su vida laboral en España y desvelar los vínculos entre la migración laboral y la presencia de retirados extranjeros en los destinos turísticos españoles, una circunstancia a la que también apuntan los datos de afiliación a la Seguridad Social española, según nacionalidades, cuando se combina esta información sobre 
afiliación con los datos de la explotación estadística del padrón. En consecuencia, podemos afirmar que la actividad turística genera una movilidad humana en la que se difuminan los límites entre trabajadores y retirados, lo que nos obliga a estudiar éstas y otras categorías como la de turista en un sentido cambiante y flexible: de turistas a retirados, de turistas a trabajadores y de trabajadores a turistas-retirados e, incluso, como migrantes laborales y migrantes retirados, al mismo tiempo.

\section{BIBLIOGRAFÍA}

BENSON, M. \& O'REILLY, K. (2009): «Migration and the search for a better way of life: a critical exploration of lifestyle migration», The Sociological Review, 57 (4), pp. 609-625.

BOZIC, S. (2006): «The Achievement and Potential of International Retirement Migration Research: The Need for Disciplinary Exchange», Journal of Ethnic and Migration Studies, 32 (8), pp. 1.415-1.427.

CASADO-DÍAZ, M.A., KAISER, C. \& WARNES, A.M. (2004): «Northern European retired residents in nine southern European areas: characteristics, motivations and adjustment», Ageing \& Society (24), pp. 353-381.

DOLADO, J.J. \& FELGUEROSO, F. (2007): «Diferencias de género y temporalidad: El caso de los profesionales superiores en el sector sanitario en España» en Mujer y diversidad en las profesiones sanitarias: Los recursos humanos en el Sistema Nacional de Salud. Fundación BBVA.

DOMÍNGUEZ MUJICA, J. (1996): La inmigración extranjera en la provincia de Las Palmas. Las Palmas de Gran Canaria, CIES.

DOMÍNGUEZ-MUJICA, J., GONZÁLEZ-PÉREZ, J. \& PARREÑO-CASTELLANO, J. (2011): «Tourism and Human Mobility in Spanish Archipelagos», Annals of Tourism Research, 38 (2), pp. 586-606.

GARCÍA PÉREZ, J.I. (2008): «Muestra continua de vidas laborales: una guía de uso para el análisis de transiciones», Revista de Economía Aplicada, XVI (1), pp. 5-28.

GUSTAFSON, P. (2008): «Transnationalism in retirement migration: the case of North European retirees in Spain», Ethnic and Racial Studies, 31 (3), pp. 451-475.

GUSTAFSON, P. (2002): «Tourism and seasonal retirement migration», Annals of Tourism Research, 29 (4), pp. 899-918.

HALL, C.M., \& MÜLLER, D.K. (Edit.) (2004): Tourism, mobility and second homes: Between elite landscape and common ground. Clevedon. Channel View Publications.

HAUG, B., DANN, G. \& MEHMETOGLU, M. (2007): «Little Norway in Spain: From Tourism to Migration», Annals of Tourism Research, 34 (1), pp. 202-222.

IOANNIDES, D. \& DEBBAGE, K. (1997): «Post-fordism and flexibility. The travel industry polyglot». Tourism Management, 18(4), 229-241.

KING, R., WARNES, A. M. \& WILLIAMS, A.M. (2000): Sunset Lives: British Retirement Migration to the Mediterranean. Oxford/New York, Berg.

LEONTIDOU, L. \& MARMARAS, E. (2001): «From tourists to migrants. Residential tourism and 'littoralization" en Apostolopoulos, Y., Loukissas, P. \& Leontidou, L. (Edit.): Mediterranean tourism: facets of socioeconomic development and cultural change. London. Routledge, pp. 257-267. 
LÓPEZ-ROLDÁN, P. (2011): «La muestra continua de vidas laborales: posibilidades y limitaciones. Aplicación al estudio de la ocupación de la población inmigrante», Metodología de Encuestas, 13, pp. 7-32.

MARTÍN ARTILES, A., LÓPEZ-ROLDÁN, P. \& MOLINA, Ó. (2011): «Movilidad ascendente d ela inmigración en España: ¿asimilación o segmentación ocupacional?, Papers, 96 (4), pp. 1.311-1.338.

MCINTYRE, N., WILLIAMS, D. \& MCHUGH, K. (Edit.) (2006): Multiple dwelling and tourism: Negotiating place, home and identity. Cambridge: CABI.

O'REILLY, K. (2003): "When is a tourist? The articulation of tourism and migration in Spain's Costa del Sol», Tourist studies, 3 (3), pp. 301-317.

O'REILLY, K. (2000): The British on the Costa del Sol: transnational identities and local communities. London, Routledge.

PARREÑO CASTELLANO, J.M.; DÍAZ HERNÁNDEZ, R. \& DOMÍNGUEZ MUJICA, J. (2011): «Crecimiento turístico-residencial y modelos autonómicos de ordenación territorial y turística en España» en Gonzálvez Pérez, V. \& Marco Molina, J.A. (Coord.): Geografía y desafíos territoriales en el siglo XXI. Alicante, Asociación de Geógrafos Españolas, Colegio de Geógrafos de España y Universidad de Alicante, vol. 2, pp. 503-514.

RODRÍGUEZ ÁLVAREZ, V. (2010): Discapacidad y mercado de trabajo: Tres análisis empíricos con la Muestra Continua de Vidas Laborales. Tesis Doctoral. Universidad de Oviedo. Departamento de Economía Aplicada.

RODRÍGUEZ, V. (2001): «Tourism as a recruiting post for retirement migration», Tourism Geographies, 3 (1), pp. 52-63.

RODRÍGUEZ, V., CASADO-DÍAZ, M.A. \& HUBER, A. (Edit.) (2005): La migración de europeos retirados en España. Madrid. Consejo Superior de Investigaciones Científicas.

SÁEZ, F. (Dir.) (2007): Panorama Laboral 2007. Itinerarios laborales en la Comunidad de Madrid. Consejería de Empleo y Mujer de la Comunidad de Madrid. Universidad Autónoma de Madrid.

SECRETARÍA DE ESTADO DE LA SEGURIDAD SOCIAL (2013): Muestra Continua de Vidas Laborales. http://www.seg-social.es/prdi00/groups/public/documents/binario/120735.pdf [acceso 22 enero de 2013]

STONE, I. \& STUBBS, C. (2007): «Enterprising expatriates: lifestyle migration and entrepreneurship in rural Southern Europe», Entrepreneurship and Regional Development, 19 (5), pp. 433-450.

VERA REBOLLO, J.F. (Coord.) (1995): Análisis territorial del turismo. Barcelona. Ariel. Geografía.

WARNES, T., KING, R. \& WILLIAMS, A.M. (2005): «Migraciones a España tras la jubilación» en La migración de europeos retirados en España. Madrid. Consejo Superior de Investigaciones Científicas, pp. 47-65.

WILLIAMS, A. \& MONTANARI, A. (Edit.) (1995): European Tourism: Regions, Spaces and Restructuring. London. John Wiley.

WILLIAMS, A. \& HALL, M. (2000): «Tourism and migration: new relationships between production and consumption», Tourism Geographies: International Journal of Place, Space and Environment, 2 (1), pp. 5-27. 